\title{
The Experience of Human Milk Donation-A Review
}

\author{
Pasqua Anna Quitadamo*, Leonilde Sorrentino, Paola Lurdo and Pierpaolo Cristalli \\ NICU, HMB “Casa Sollievo della Sofferenza” Hospital, Italy
}

Submission: December 20, 2019; Published: January 22, 2020

*Corresponding author: Pasqua Anna Quitadamo, NICU, HMB “Casa Sollievo della Sofferenza” Hospital, San Giovanni Rotondo, Italy

\section{Introduction}

The provision of donor human milk is recommended by the World Health Organization as the best option when a mother's own milk is unavailable, because can significantly reduce morbidity and mortality among vulnerable infants. For preterm babies, human milk banks (HMBs) offer a lifesaving alternative to ensure timely access to human milk. Why does a mother donate her own milk? This is a question that some authors have asked themselves because from the motivation of a spontaneous gesture can start the understanding and activation of the mechanisms necessary to improve donation promotion strategies. This is the objective, for example, of a descriptive study [1] which aims to identify reasons, beliefs and feelings related to the donation based on the reports of women donors. The most frequent response from HMBANA donor mothers (Human Milk Association of North America) lies in altruistic reasons [2]. In a study conducted in Brazil [3], the leader country with the largest network of milk banks in the world, the most common reasons behind milk donation are the encouragement from health personnel with more than $60 \%$ of the 737 women interviewed, followed by the needs of children receiving milk from the bank with $25.3 \%$. Therefore, the staff plays a fundamental role in motivating mothers to donate milk. This is probably the result of the fact that the recruitment of new donors, the increase in the volume and frequency of donations has become a priority in many Brazilian milk banks. For this, a prenatal care is carried out which, in addition to regular promotion and information on breastfeeding, combines regular preparation on the donation of the surplus milk as indicated by the World Health Organization and United Nations Children's Fund. On the contrary, in a Turkish study [4] that aims to assess the knowledge and point of view of mothers with respect to milk banks, through a questionnaire addressed to 440 mothers, $41 \%$ had been informed of this reality through the media for about $90 \%$, while a minimum share received this information from healthcare professionals. It is emphasized that the media is the main source of breastfeeding promotion and that in recent decades media interest in milk sharing has grown considerably. The important fact of the work regarding the mothers' point of view is that $70 \%$ showed to be in favor of the bank and of the possibility to donate.
A similar perception is reported by a group of Australian mothers of a small pilot study [5] that wants to explore their knowledge and attitudes regarding breast milk donation and banking, in a land that is surprisingly far behind the rest of the world on this aspect: in the South of the country there are no milk banks. The women interviewed showed to be highly sensitive to the topic and available to the possibility of donating, indicating as a real need the fact to activate a promotion that should start from health professionals who represent the first and most authoritative source of information regarding child nutrition and to publicize this reality to make it more widely known. 97 donors from North America, Europe, Oceania and Asia participated in a study [6] that evaluates the reasons for milk donation through a milk sharing network on the Net. The reasons of the donation are basically with a clear prevalence of altruistic reasons followed by practical ones. In particular, 71 of them were motivated by the desire to help newborns, their mothers and their families, 59 from the excess of milk beyond the needs of their own child, 37 do not want their milk to be lost, 33 believe that human milk is important for the properties that artificial milk does not have, 15 were inspired by individual stories, 12 of them put themselves in the shoes of women who can't produce enough milk considering it a terrible event, 9 would have liked someone to give them milk if they had been unable to produce it, 5 had previously had a similar experience due to insufficient production. In a Chilean study carried out for the purpose of interpret the perception about experiences, beliefs, and attitudes towards the donation of breast milk in woman from a hospital, they have presented knowledge of the act of donating milk, emphasizing an altruistic paradigm. They associated this act with generosity, especially for infants who do not have access to breast milk directly from their mothers [7].

The conclusions of an exploratory, cross-sectional, descriptive study are very interesting. In fact it was concluded that humanized institutional care, permeated by the actions of encouragement and improvements in the communication process about donation, associated with social support from people significant to the donor, could help to strengthen the human milk donation network and that the improvement of institutional/organizational processes 
and the training of human resources engaged in this area may increase the quality of the network of milk banks [8]. In a recent report a decision tree has been developed for using clinicians and experts in human milk banking and neonatal care, to help guide prioritization and allocation of DHM, as well as evaluate barriers to feeding with mother's own milk [9]. From the analysis of the interviews emerged an understanding that the value the participants placed on breastfeeding, human milk, and the practice of donation are the main motivations for donating human milk. Although the interviewees experienced some difficulties donating their milk, the rewarding feeling, the value the women placed on the act of donating, and the support they received from people important to them were essential to pursuing milk donation. The findings also provide clues about possible obstacles to attracting potential donors by revealing weaknesses in the completeness of the health services provided to these women during prenatal care in relation to milk donation [6]. In another qualitative study done in Hong Kong adopting in-depth ten semi-structured interviews with the aim to explore the perceptions on breast milk donation and establishment of breast milk banks among breastfeeding mothers, most of them welcomed the idea of breast milk donation and the establishment of breast milk bank. Thus, nurses are recommended to increase their knowledge of breastfeeding to encourage mothers to continue breastfeeding and monitor the breast milk bank in the future. Nurses also play an important role in the promotion of arousing the public attention about the establishment of breast milk bank in Hong Kong [10].

\section{The donation of mothers of preterm babies}

The milk of mothers of premature babies is different, richer in proteins and more caloric in order to better meet the needs of a preterm baby that grows rapidly and is still vulnerable. Might the mothers of premature babies donate some milk to the HMB? There is no bibliographic entry on this subject, except for one of our works [11] where it is reported that $13 \%$ of the donation in 5 years of human milk banking activity comes from the mothers of premature babies-of this percentage around $40 \%$ comes from women who delivered at gestational age $<25$ weeks and $36 \%$ from mothers of newborns with birth weight $<500$ grams. The only other references are anecdotal cases of donation by mothers who weren't able to give their child milk because dead or sick [12-15]. Welborn described in a study the experience of 21 [12] mothers who donated their milk for free to the milk bank for a shorter or longer period after the loss of a child into uterus or after birth. It should be noted, however, that 15 mothers donated milk when their babies were in NICU unable to be fed. The motivation lies in their words, reported in the questionnaire of the study: "the only thing I can do is to give my love and my milk". The main feeling of these women, collected in another work [13] that involved 14 mothers who were pulling the milk during their pre-term children's stay in NICU), is that the offer of milk can reduce the natural separation-connection paradox that accompanies the birth and is exasperated with premature birth. This aspect is further declared in a review [14] which deals precisely with the feelings and needs of women expressing milk in NICU. Mothers who have lost their children before or after birth recognize that extracting milk is a way to maintain a physical connection with them [12]. For some, even the expression of milk by squeezing is a profound way to feel like a mother in the absence of her child [15]. A woman who donated her milk to the Denver milk bank for 6 months after the death of her baby reported that milk was needed to keep her baby's memory alive and helped her establish a multidaily connection with his son. Other mothers used milk expression and donation as a means to transcend pain by feeding other infants with their milk [16]. Exceptional and unique is the case [17] of an adoptive mother who, besides breastfeeding her child for 6 months and up to 2 years of life, has become a donor of the milk bank. The main motivation in trying to induce lactogenesis is to try to establish a contact with the adopted child and feed him with the precious mother's milk, because breastfeeding is a time of profound intimacy between mother and child. According to our experience, if there is motivation from women, and if the protocols concerning breast stimulation are respected (within 6 hours of birth and every 3 hours thereafter, eight times a day), the possibility of breastfeeding premature infants is high [11].

\section{References}

1. Alencar LC, Seidl EM (2009) Breast milk donation: women's donor experience. Rev Saúde Publica 43(1): 70-77.

2. Candelaria LM, Spatz DL, Giordano N (2018) Experiences of Women Who Donated Human Milk. J Obstet Gynecol Neonatal Nurs 47(4): 556563.

3. Pimenteira Thomaz AC, Maia Loureiro LV, da Silva Oliveira T, Furtado Montenegro NC, Dantas Almeida Júnior E (2008) The Human Milk Donation Experience: Motives, Influencing Factors, and Regular Donation. J Hum Lact 24(1): 69-76.

4. Ekşioğlu A, Yeşil Y, Turfan EC (2015) Mothers' views of milk banking: sample of İzmir. Turk Pediatri Ars 50(2): 83-89.

5. Mackenzie C, Javanparast S, Newman L (2013) Mothers' Knowledge of and Attitudes toward Human Milk Banking in South Australia: A Qualitative Study. J Hum Lact 29(2): 222-229.

6. De Miranda WD, Passos MC, de FátimaFreitas MI, de FátimaBonolo P (2016) Representations of women milk donors on donations for the human milk bank. Cad. Saúde Colet 24(2): 139-144.

7. Ibarra Peso J, Meza Vásquez S, Aguayo Gajardo K (2018) Experiences, beliefs and attitude on donation of human milk in women of Arauco province. Rev Chil Pediatr 89(5): 592-599.

8. De Alencar LC, Seidl EM (2010) Breast milk donation and social support: reports of women donors. Rev Lat Am Enfermagem 18(3): 381-389.

9. Brandstetter S, Mansen K, DeMarchis A, Quyhn NN, Engmann C, IsraelBallard K (2018) A Decision Tree for Donor Human Milk: An Example Tool to Protect, Promote, and Support Breastfeeding. Front Pediatr 6: 324.

10. Leung JCY, Yau SY (2015) Perceptions of Breastfeeding Mothers on Breast Milk Donation and Establishment of Human. Breast Milk Bank in Hong Kong: A Qualitative Study. International Journal of Nursing 2(2): 72-80. 
11. Quitadamo PA, Palumbo G, Cianti L, Napolitano ML, Coviello C, et al (2018) Might the Mothers of Premature Babies Feed Them and Devote Some Milk to the Milk Bank? International Journal of Pediatrics 2018.

12. Welborn JM (2012) The experience of expressing and donating breast milk following a perinatal loss. J Hum Lact 28(4): 506-510.

13. Flacking R, Ewald U, Nyqvist KH, Starrin B (2006) Trustful bonds: a key to becoming a mother and to reciprocal breastfeeding. Stories of mothers of very preterm infants at a neonatal unit. Soc Sci Med 62(1): 70-80.

14. Flacking R, Ewald U, Starrin B (2007) I wanted to do a good job: experiences of 'becoming a mother and breastfeeding in mothers of

This work is licensed under Creative

Commons Attribution 4.0 Licens

DOI: 10.19080/AJPN.2020.08.555804 very preterm infants after discharge from a neonatal unit. Soc Sci Med 64(12): 2405-2416.

15. Killersreiter B, Grimmer I, Buhrer C, Dudenhausen JW, Obladen M (2001) Early cessation of breast milk feeding in very low birthweight infants. Early Hum Dev 60(3): 193-205.

16. Carroll KE, Lenne BS, McEgan K, Opie G, Amir LH, Bredemeyer S, et al. (2014) Breast milk donation after neonatal death in Australia: a report. Int Breastfeed J 9(1): 23.

17. Flores-Antón B, García-Lara NR, Pallás-Alonso CR (2017) An Adoptive Mother Who Became a Human Milk Donor. J Hum Lact 33(2): 419-421.

\section{Your next submission with Juniper Publishers will reach you the below assets}

- Quality Editorial service

- Swift Peer Review

- Reprints availability

- E-prints Service

- Manuscript Podcast for convenient understanding

- Global attainment for your research

- Manuscript accessibility in different formats

( Pdf, E-pub, Full Text, Audio)

- Unceasing customer service

Track the below URL for one-step submission https://juniperpublishers.com/online-submission.php 